patients, and will use your influence, donations and legacies will come in, and in the course of time we shall take a step in the right direction.

3. Exercise-Exercise is one of the most powertul and essential means of cure. It is as necessary as air and food, because it enables the invalid to take both in a sufficient quantity to improve the nutrition by taking up fresh material and removing the waste, and thus to fight a battle with a fair chance of success. Without exercise I should not like to treat phthisis. To take exercise properly requires, however, the guiding hand of the physician; there are judicious persons who can be taught to become sufficiently acquainted with their entire condition and their surroundings to enable them to do neither too much nor too little, but such persons are rare amongst consumptive invalids. In many of them the nutrition of the brain has suffered as much as that of the scomach and lungs and other systems, and their judgment with regard to their own state and their wants is impaired. We ought, therefore, to bear in mind that by far the majority of those suffering from phthisis require constantly to be held by "leading reins," and must be told what kind of exercise to take, how much, and at what times; walking on level, climbing gently, and with measured increase as to duration and steepness. Riding on horseback, skating, and tobogganing are all useful exercises under guidance, but over-exertion ought to be carefully avoided, and one mistake often destroys the fruit of months and years of judicious management. Up to a certain point the sense of fatigue is a guide, but not always, for some persons feel fatigue at the beginning of a walk and improve while taking it, and others never acknowledge to themselves the sense of fatigue. The medical man alone can measure the amount of strength, and how it can be maintained and increased by gradually increasing exercise. Climbing is especially useful, as it brings the whole systems of circulation and respiration into play, and leads to expansion of the lungs and thorax and strengthening of the respiratory muscles. Regulated climbing for a course of weeks and months in suitable cases has a wonderful effect on every organ and function of the body; not only respiration and circulation, but the digestion, the action of the skin, sleep, mental power, resistance to changes of temperature, all show the beneficial effect, and we scarcely doubt that this is due to an improvement of Beale's bioplasm, or "living matter," in the cells. Riding on horseback is likewise excellent exercise, exhilarating and accelerating the circulation, and through this the respiration; and it has been the principal means of treatment in several cases of recovery under my observation (Sydenham). Riding on donkeys may, in some localities, be substituted for horse exercise. Tricycling is likewise useful to some invalids. Pulmonary gymnastics-i.e., a methodical deep inspiration, followed, after a pause, by full expiration, practised in pure air several times a day are very useful in chronic non-febrile cases. Well-arranged exercises of the upper extremities materially assist the expansion of the apices and the subclavicular regions. Where active exercise is impossible from great weakness, or forbidden from inflammatory complications, the movement in a Bath chair is especially to be recommended, and by turning the head against the wind it can be used in almost all weathers. Open carriage exercise is likewise good, but there ought to be very little wind, or some arrangement for sheltering from the wind, by having, for instance, the front hood up, and sitting with the back to the horses, which can be well arranged in landaus. Those who have the chance of being moved in a boat up and down a river, or on calm days on the sea, often derive great benefit from this mode of motion. In some cases under my observation well-arranged journeys, in agreeable company, in rowing-boats, or small yachts, or steamers up the Thames, the Rhine, the Main, the Neckar, the Danube, the Isar, the Seine, and Meuse, have had very beneficial effect on body as well as mind, and the latter ought never to be forgotten in phthisis. In some very chronic cases of nerve prostration, with inability to walk and to take food in sufficient quantity, massage can with advantage take the place of active exercise, being a powerful accelerator of tissue-change, and leading to increased breathing and improved circulation. I have as yet had only a few cases in which I have recommended a plan somewhat analogous to that of Weir Mitchell and Playfair, though very much less energetic, but with evident advantage on the nutrition, muscular and and mental energy. It appears to me, so far as my experience goes, that there should be no active lung symptoms. The open-air treatment has been combined in those cases with massage, the patients having been placed during a greater part of the day on couches in the balcony, or in the garden. Walking exercise was not allowed during the first part of the massage treatment, but was gradually substituted for it.

4. Strengthening of the Skin.-Weakness of the skin is one of the prominent features as well in the tendency to phthisis as also in the developed disease, and ought always to be taken into consideration and remedied if possible. A slight change of external temperature, or exposure to a slight draught or change of clothing is apt to produce chill, which by reflex action is thrown on the lungs; it is also a frequent source of bronchitis and catarrh of the lungs, and also of digestive derangements and a great obstacle to recovery in phthisis. Constant exposure to the open air and exercise are the best tonics for the skin, and often suffice by themselves; but in many cases these must be combined or preceded by the judicious use of hydro-therapeutics. The skin has never been altogether neglected in England either by medical men or the public, while on the Continent the neglect has been incredible, and is still so in many localities, hence systematic hydro-therapeutics have had their origin on the Continent; and in the treatment of phthisis too Brehmer was the first to introduce them with special modifications,--viz., powerful cold douches to the chest of very short duration. Unger, Spengler, Dettweiler and others have continued and modified this system; Jaccoud, Sét, and other French physicians are powerful advocates for hydro-therapeutics. Much benefit is no doubt obtained by well-adopted procedures, but they require most careful management by the medical man. Even the ordinary treatment of the skin in itself ought to be guided by the doctor, who will not onl examine the state of the skin, but also the condition of the heart and circulation in all its bearings; the degree of reactive power must be cautiously appreciated and gradually raised. In great weakness dry rubbing by an attendant of one part of the body after another is all that can be done; then rubbing the chest with a moist towel, and dry rubbing afterwards. Later on a very rapid sponging with tepid, and again later with cold, water, followed by a short return to bed, and a light, warm breakfast. It requires a considerable degree of reactive force to bear with advantage on rising in the morning the sponging of the whole body by cool or cold water, followed by brisk friction as daily practised by the majority of us in health, and forcibly recommended by J. Henry Bennet, whose views on the hygiene of phthisis have exercised good influence. A rapid plunge into cold water is in many cases of fair reaction the best plan. In others a very short shower bath, and, again, in others a tepid bath for a couple of minutes, followed by a momentary cold shower or plunge into cold water. Many sound hints on bathing and on the management of the skin may be gathered from the editor of the "Book of Health," in his article on the skin. Although by this means the skin becomes strengthened, yet the invalid ought never to neglect woollen clothing from head to foot. He ought not to overload himself with heavy garments while walking or riding, but he ought to have plenty of warm wraps when he sits down or takes passive exercise. The influence of dress on health has been well discussed in a paper by Mr. F. Treves in the "Book of Health," and Pettenkofer's little book, translated into English by A. Hess, is full of useful information.

\section{CASE OF ANEURYSM BY ANASTOMOSIS ON} THE HEAD,

TREATED BY LIGATURE OF THE COMMON CAROTID ARTERY, AND SUBSEQUENT LOCAL LIGATION.

By G. B. FERGUSON, M.D., \& G. A. CARDEW, M.R.C.S., SURGEONS TO THE CHELTENHAY HOSPITAL AND DISPEXSARX.

ANNIE S- - aged nineteen, came first under the observation of Mr. Cardew at the Cheltenham Dispensary, in November, 1881. She then complained of a pulsating swelling at the back and right side of the head, involving also the right ear, which was greatly enlarged. She had had some swelling about that position throughout the whole of her life, the first stage having been a nærus, which had never been subjected to any treatment. During the twelre 
months previous to her seeing Mr. Cardew the tumour had increased rapidly in size, and had frequently burst, severe hæmorrhage in each case ensuing. The patient was a strong-looking girl of short stature, who, with the exception of occasional headaches, had enjoyed excellent general health. On examination, a considerable tumour was visible, evidently a cirsoid aneurysm, otherwise styled aneurysm by anastomosis, extending from the back of the right ear to the occipital protuberance, and extending as high and descending as low as the upper and lower borders of the temporal bone, occupying, in fact, about twenty square inches. The tumour was of a pulpy consistence, and pulsated forcibly, as also did the ear. A loud thrill was audible over it. It was covered with small and thin-walled venous projections, which were the sites of the frequent hæmorrhages. After a specially severe and dangerous hæmorrhage about the middle of December, 1881-she was stated then to have lost about three pints,--her friends and herself became seriously alarmed, and requested the institution of some radical treatment. Accordingly she was shortly afterwards admitted into the Cheltenham Hospital, and came under the care of Dr. Ferguson. There, after due consultation, it was decided that the common carotid artery should be tied, and this was accordingly done in the ordinary manner and with the full Listerian precautions that have been employed by all the surgeons of the Cheltenham Hospital since the year 1876. The operation presented no difficulty, and calls for no remark save that, the omo-hyoid muscle passing apparently somewhat higher than is usually the case across the neck, it was easier to secure the artery below than above the muscle in which former position it was accordingly reached and tied. The ligature was of chromic catgut of medium thickness, most obligingly sent to Dr. Ferguson by Sir Joseph Lister. And in order that his kindness should not be unnecessarily trespassed on hereafter, we would desire in this place to repeat Sir Joseph's information, that chromicised catgut of identical quality can be supplied by David Marr of Holborn. 'The patient's progress after the operation was typically satisfactory, there having been neither pain nor any (even the most trifling) elevation of temperature. In fact, the dressings were finally removed on the eleventh day after the operation, exposing then the firm cicatrix of a wound that had evidently healed by first intention. The immediate result of the operation was the shrinkage, almost to disappearance, of the tumour and the complete cessation of the pulsation. It was, therefore, no small disappointment to notice after the removal of the dressings that a slight pulsation was again perceptible over the site of the tumour. However, she was shortly afterwards dismissed from the hospital in good health and spirits and well pleased at the result of the operation. During the next six months her history presented no points of special interest, save that the tumour became still less noticeable, and that the pulsation remained obscure. But after this six months' period of quietude a collateral circulation succeeded in establishing itself to a somewhat considerable extent, and the tumour began again to in crease and pulsate somewhat after its former fashion (though much less forcibly), and there was even some recurrence of hæmorrhage. This being the case, Mr. Cardew (to whose care she had returned) determined to ligature the tumour subcutaneously. One half of the tumour was accordingly ligatured with a silk thread in the usual manner, the latter being tightly tied. The result was the entire stoppage of the pulsation in the part tied. The silk was tightened every day for ten days, after which time, when it had almost cut its way out, it was removed. This process of ligation brought about a notable consolidation of one-half of the tumour, and this at the expense of but little pain or suppuration. Some few days afterwards the posterior auricular artery was ligatured on a pin, which had been first passed under it, this step being taken in consequence of its large size and evident connexion with much of the remaining pulsation. Two months later the other half of the tumour was similarly ligatured subcutaneously, and again, six weeks later, as an additional safeguard, the whole was once more subcutaneously re-ligatured. With this last ligation the treatment ended, almost complete obliteration of the tumour having been effected, with an entire removal of the hæmorrhagic tendency; and on inspection of the patient on March 7th, 1884, and eighteen months after the cessation of treatment, it was evident that a substantial cure had been effected. Some slight softness only was apparent at the position of the former growth, but there was no feeling of pulsation anywhere, save over an artery in the position of the occipital, and the ear, which was formerly so tumid, had returned to a moderate size. The hæmorrhagic tendency had not again manifested itself, and the patient's health and spirits were of the best.

Remarks. - The chief interest of this case lies in its close resemblance to the one treated by Mr. Storks and Sir William Fergusson, and narrated in the latter's System of Practical Surgery (p. 151), where much information respecting such cases will be found. Sir William Fergusson, however, trusted more to obliteration of the vessels in the growth by pins and ligatures, and Mr. Cardew to ligation en masse. In respect to all such cases it may be doubted if the treatment by pins or direct ligation could be safely applied without the preliminary tying of the chief nutrient artery, in reference to which question the following remarks of Sir William Fergusson are much to the point. "The practice above described was certainly attended with considerable hazard, both on account of the inflammation as well as the hæmorrhage, and it was not without misgivings that I adopted it. But the case seemed otherwise hopeless, and the previous obliteration of the common carotid led me to trust that such bleeding as might occur could be controlled. Without this preceding step it may be doubted if the result would have been equally successful; and I am therefore disposed to attribute the satisfactory issue to a combination of the two methods-viz., first, the obliteration of the main arterial current towards the disease, and then the destruction of the vessels in its substance." It is interesting, finally, to note the success of both these cases in the face of Billroth's direct condemnation of the treatment pursued (Surgical Pathology, vol. ii., p. 337), as interesting as it is to remember that the treatment which was written about so warningly by John Bell is that very one of extirpation most highly commended by Billroth.

Cheltenham.

\section{THE BACILLUS OF SYPHILIS. ${ }^{1}$}

BY DR. SIGMUND LUSTGARTEN,

FIRST ASSISTANT TO PROFESSOR KAPOST IN THE DERMaTOLOGICAL WAR DS OF THE VIENTA GEXERAL HOSPITAL.

Translatfo by DR. J. N. Bloom, B.A., M.D.

SINCE Hallier's time, a period of almost twenty-five years, the virus of syphilis has been the subject of frequent communication and of almost constant discussion; but, nevertheless, the conviction is universal that none of these researches have even partially solved the question, because of their countless contradictions, inefficient methods, and errors that are easily recognised. And further, as my effort is not the continuation of any preceding one, I will not tax your time and patience by a review of the literature of the subject, but will at once detail my own observations, referring for the literature and development of the subject to a publication of mine shortly to appear. ${ }^{2}$

My researches with syphilitic products have led to the discovery of micro-organisms which until now were unknown, which are constant in their appearance, and which are thoroughly characteristic. They approach nearest in their morphological appearance and staining reaction to the bacilli of leprosy and tuberculosis, and, like these, are to be found in granulomata. By means of the method about to be given they appear as straight or curved, and sometimes irregularly bent rods, which are on an average from three and a half to four and a half micro-millimetres long, and from one-fourth to three-tenths thick. With a low power they appear uniformly smooth, presenting here and there a bulbous swelling at their extremities. With a homogeneous immersion lens (one-twentieth of an inch, Reichert) their surface appears irregularly undulatory, and slightly notched, yet in a manner such as to leave no doubt as to their rod nature. Within them we recognise, at equal distances from one another, oval, colourless, bright spores, from two to four in every bacillus. I never saw the bacilli lying free, but always enclosed in cells. These cells are from a triffe larger than, to double the size of, white blood-

1 A paper read before the Royal and Imperial Society of Physicians of Vienna, on March 27th, 1885 .

2 Die Syphilis Bacillen, Wiener Medizinische Jahrbucher, first quarter, 1885; also as a brochure about to be printed by Braumueller, Wien. 